\title{
POSSIBILITY FORECASTING OF PROGRESSIVE NEUROLOGICAL AND PSYCHOPATHOLOGICAL DISORDERS IN CHRONIC MERCURY INTOXICATION
}

\author{
Elena V. Katamanova \\ Clinic Department \\ FSBSI «East-Siberian Institute of Medical and Ecological \\ Research» \\ Angarsk, Russia \\ krisla08@rambler.ru
}

\author{
Viktor S. Rukavishnikov \\ Department of Management \\ FSBSI «East-Siberian Institute of Medical and Ecological \\ Research» \\ Angarsk, Russia \\ rvs_2010@mail.ru
}

Oleg L. Lakhman

Clinic Department

FSBSI «East-Siberian Institute of Medical and Ecological Research»

Angarsk, Russia

lakhman_o_1@mail.ru.

\author{
Oxana I. Shevchenko \\ Department of Professional-related Diseases \\ FSBSI «East-Siberian Institute of Medical and Ecological \\ Research» \\ Angarsk, Russia \\ oich68@list.ru
}

\author{
Salim F.Shayakhmetov \\ Department of Management \\ FSBSI «East-Siberian Institute of Medical and Ecological \\ Research» \\ Angarsk, Russia \\ aniimt_clinic@mail.ru
}

\begin{abstract}
Objectives of the research was to identify the most informative criteria of progression of chronic mercury intoxication and the possibility of its prediction using neuropsychological and neurophysiological methods. For research were chosen 3 groups of patients with different degrees of severity of mercury intoxication. It is conducting a study of the emotional sphere, using the technique MMPI and the level of depression according to $\mathrm{V}$. Zung, neuropsychological testing, EEG with the definition of auditory, visual, cognitive evoked potentials, somatosensory evoked potentials were assessed. Informative criteria were calculated using discriminant analysis. The main markers of pathological changes in the early stages of the disease in an internship working in contact with mercury for more than $\mathbf{1 0}$ years, are: exceeding the normative values of $2^{\text {nd }}$ and $8^{\text {th }}$ scales MMPI from 70 points and more, exceeding the level of depression $V$. Zung from 54 points or more, reduction of attention concentration below 279 points, increase in the indicator of long-term, visual memory, finger gnosis and impressive speech from 0.5 points and above, and an increase in latency peak N11 somatosensory evoked potentials of $12 \mathrm{~ms}$ or higher, the increase in $P 2$ visual evoked potentials from $260.0 \mathrm{~ms}$ and above, and decrease in the index of alpha rhythm on the EEG below 32\%. With the combination of all four of these indicators of the likelihood of mercury poisoning
\end{abstract}

was $91.3 \%$. To predict the development of psycho-neurological symptoms, patients in contact with the mercury, it is necessary to conduct an annual comprehensive examination, including neuropsychological and neurophysiological methods.

Keywords - occupational chronic mercury toxicity, progression of the disease, psychiatric disorders.

\section{INTRODUCTION}

At present much attention is devoted to the formation of mental health problems at workers of chemical enterprises in contact with neurotropic poisons (mercury, manganese, lead, etc.), because as a result of improving working conditions and reducing the concentration of toxic substances in the air of the working area, the clinical picture of occupational intoxication dominated latent form, complicating the differential diagnosis with other neurointoxications and diseases of the central nervous system that occur with asthenic-vegetative syndrome and disorders of mental health problems, which are often all diagnosed only through psychological research. It is known that in the long term neurointoxications leading place is occupied psychopathological alterations $[1,2,3]$. Formation 
of organic personality disorder occurs on a background of high levels of depression and asthenic condition. The intensity of anxiety and depressive disorders reflects the dynamics of intellectual-mental disorders, leading to psychological and emotional maladjustment of personality, which is one of the most informative clinical criteria in the development of pronounced forms of chronic mercury intoxication (CMI) in the post-exposure period, and for the diagnosis of such changes usually resort to neuropsychological testing patients [4].

Highly informative for the diagnosis of neurological disorders in CMI have neurophysiological research methods. So, during the EEG in patients with signs of toxic encephalopathy in the CMI is dominated by diffuse changes with the formation of foci of pathological activity; often detected paroxysmal activity $(87 \%)$. When registering visual evoked potentials observed lengthening of latency P 200, which indicates a deterioration of cognitive functions [5]. In addition, when electroneuromyographic examination of patients with a diagnosis of CMI, especially in disease progression and build-up of psychopathological and neurological disorders, revealed pathological changes in the functioning of peripheral nerves in the upper and lower extremities. There is decrease in conduction velocity impulse and an increase in residual latency of the proximal and distal parts of the nerves of the upper and lower extremities. Reducing the speed conducting impulse reflects the process of demyelination, increased residual latency indicates a change in the status of the end unmyelinated fibers [6].

Therefore an object of this research was to identify the most informative criteria for progression of chronic mercury intoxication and the possibility of its forecasting.

\section{MATERIALS AND METHODS}

For research were matched groups of patients with different limitation period of contact with the mercury, and in varying degrees damage to the nervous system (from prenosological forms to remote consequences CMI). The first group (I) - 30 trained workers who were in contact with the mercury, without a specific diagnosis of occupational CMI, with an average age $-46.1 \pm 7.5$ years and the average work experience in hazardous conditions $17.05 \pm 1.1$ years. The second group (II) - 17 people with newly diagnosed occupational CMI, with an average length of service in hazardous conditions $-15.7 \pm 1.7$ years, average age $-49.6 \pm 6.0$ years. The third group (III) -36 patients in a remote (postexposure) period CMI. The average age of patients in this group amounted to $-50.8 \pm$ 6.0 years, with an average experience in contact with the metal mercury $-14.7 \pm 1.05$ years. This group of patients observed over the last 10 years, since the establishment of an occupational disease, and stop contact with the mercury. Practice has shown that CMI even after the termination of mercury tends to progression of the neurological and psychiatric symptoms, it was necessary to establish indicators that reflect the severity of the disease worsening.

IV (control group) - healthy men of 30 people - a representative of persons (mean age $-47.2 \pm 4.7$ years) and the general seniority $(14.2 \pm 1.2$ years $)$ who do not have a professional route of contact with harmful substances.

Was conducted neuropsychological study by A.R. Luria. It was evaluated condition of intelligence, memory, praxis, gnosis and speech [7]. Evaluation the severity of disorders of psychological indicators for each procedure carried out on a 4-point scale: 0- norm 1 - light-, 2 - moderate, 3 significantly expressed infringements [7]. To assess the character traits of the person (accentuation) and identify psychopathological changes are applied standardized multivariate method MMPI, adapted L.N. Sobchik, 1990. The level of depression (LOD) was determined on a scale based on the questionnaire of V.Zung adapted by T.N. Balashova, attention was assessed by proofreading sample "Landolt Rings" [8].

Registration somatosensory evoked potentials (RSEP) was carried out with the right stimulation of the median nerve in the wrist on the basis electroneuromyography "Neuro-EMG-Micro" company 'Neurosoft', the city of Ivanovo. Electroencephalography (EEG), long-latency visual (VEP), cognitive evoked potentials (CEP) were carried out on a computer multifunctional complex for EEG and EP "Neuron-Spectrum-4", LLC "Neurosoft ', Russia.

Statistical analysis was performed using the program «Statistica 6.0». After analyzing of compliance the study parameters to the law of normal distribution (Shapiro-Wilk test), comparison groups was performed using the MannWhitney test for pairwise comparisons of unrelated samples. The results of the study are presented as median (Med), the upper (Q25) and lower (Q75) quartiles. Differences were considered statistically significant at $\mathrm{p}<0.05$. To identify the informative signs of forecasting CMI was used discriminant analysis. The informativeness of the analyzed indicators were determined by step procedure, the initial setup parameters made in accordance with the recommendations of Borovikov V. (2001). Boundary value $F$ to activate the selected value of $F \geq 3,5$. Significant figures were considered at odds of informativeness of more than $80 \%$ (the probability of development / progression) [9].

The survey of patients corresponded ethical standards in accordance with the Declaration of Helsinki of the World Association "The ethical principles of medical research involving human subjects", as amended in 2000 and "Rules of clinical practice in the Russian Federation" approved by Order of Ministry of Health of the Russian Federation №266 of 19.06.2003.

\section{RESULTS AND DISCUSSION}

The clinical picture of the pathology of the nervous system of people of the first group was mainly presented asthenic (emotional lability) disorder $(69.5 \pm 8.3 \%)$ with autonomic dysfunction syndrome with peripheral autonomic disorders in the limbs, cardiovascular disorders (56.5 $\pm 7.5 \%)$. In $34.7 \pm 5.8 \%$ of cases in this group was determined by mercury in bioenvironments above the standard indicators. Cognitive disorders, revealed by psychological testing, were mild and occurred in $21.7 \pm 4.6 \%$. 
In group II, professional chronic mercury intoxication was set at $100 \%$ of the cases, a CMI stage I $-85.7 \pm 9.3 \%$ and II stages of intoxication $-14.3 \pm 2.7 \%$ of patients. Toxic encephalopathy was diagnosed in $16.7 \pm 8.8 \%$ of patients, organic personality disorder in $5.5 \pm 5.4 \%$, cognitive impairment in $61.1 \pm 11.5 \%$, shaking hyperkinesia in $38.8 \pm$ $11.5 \%$, pyramidal syndrome in $11.1 \pm 7.4 \%$, vestibulo-ataxic syndrome in $11.1 \pm 7.4 \%$, polyneuropathy of extremities in $11.1 \pm 7.4 \%$ of patients. Psychopathological changes were manifested in the form of emotionally labile disorder (94.4 $\pm 5.4 \%$ ). In bioenvironments in $66.7 \pm 11.1 \%$ of cases determined by the mercury above the normal values.

In group III among patients in the long term CMI - I stage of the disease was recorded in $8.4 \pm 2.6 \%$ of cases, II stage - in $89.3 \pm 9.7 \%$ and stage III in $2.3 \%$ of cases. The frequency of toxic encephalopathy was $91.6 \pm 9.9 \%$, organic personality disorders and cognitive impairments $-80.5 \pm$ $9.2 \%$. Asthenic disorders was revealed in $29.4 \pm 4.5 \%$ cases, autonomic dysfunction in $55.6 \pm 5.7 \%$ cases, hyperkinetic syndrome in $22.2 \pm 4.3 \%$, polyneuropathy extremities of $5.6 \pm$ $2.7 \%$, vestibulo-ataxic disorders in $33.4 \pm 4.7 \%$, pyramidal syndrome $5.6 \pm 2.2 \%$ of patients.

The first phase was carried out discriminant analysis among indicators that characterize the emotional sphere, and personality traits. Based on the analysis was obtained 6 prognostic criteria: 3 on a scale indicator MMPI - F, 2, 8, (TScore); concentration of attention (score); the level of depression (score); figure figurative memory (score). F inclusion for indicators obtained ranged from 24.4 ( $\mathrm{p}=$ $0.001)$ - indicator F in MMPI, to $5.0(\mathrm{p}=0.05)$ - indicator 2 of MMPI.

Table 1 shows that the emotional sphere is the most vulnerable when exposed to the mercury on the nervous system, this is a confirmation of the excess of regulatory values of 2 and 8 scales of MMPI, and the level of depression in the group of trained workers (group 1), without a diagnosis of mercury intoxication. At high values of 8th scale is usually detected difficulty of social contacts, cruelty, aggressiveness, blurred thinking, confusion, originality of psychic experiences, the gap between the real, the uniqueness of perception, judgment, feelings. The combination of increasing T-scores in the 2nd and 8th scales indicates a depressive reaction, violation of social adaptation and loss of productivity, decreased motivation activities. Subsequently, with the appearance of clinical symptoms of chronic mercury intoxication join cognitive impairments, reduced of figurative memory from 8.1 to 6.2 and 5.5 points ( $\mathrm{p}<0.05$ ), respectively, between 1, 2 and 3 groups; concentration of attention from 354.0 to 169.0 points ( $p$ $<0.05$ ), respectively, between 2 and 3 groups, and emotionalvolitional disorders continue to worsen - the values on the scale 2 MMPI grow from 81.0 to 92.6 , and up to 103,6 points, respectively, between 1,2 and 3 groups $(p<0.05)$ (Table 1).

The defeat of the nervous system in mercury intoxication is always diffuse character and is characterized by significant variability of localization coverage pathological process of various brain structures and clinical manifestations [10, 11].
TABLE I. INDICATORS OF EMOTIONAL AND COGNITIVE AREAS OF SURVEYED IN GROUPS, ME (Q25-Q75).

\begin{tabular}{|c|c|c|c|c|}
\hline $\begin{array}{l}\text { Indicators, } \\
\text { scores }\end{array}$ & $\begin{array}{c}\text { 1st group } \\
(\mathrm{n}=30)\end{array}$ & $\begin{array}{c}\text { 2nd group } \\
(\mathrm{n}=17)\end{array}$ & $\begin{array}{c}\text { 3rd group } \\
(n=36)\end{array}$ & $\begin{array}{l}\text { Control } \\
\text { group } \\
(\mathrm{n}=\mathbf{3 0})\end{array}$ \\
\hline Depression & $\begin{array}{c}54.5(50.0- \\
62.0) *\end{array}$ & $\begin{array}{c}64.9(56.0- \\
70.0) * \circ\end{array}$ & $\begin{array}{c}\text { 67.4(59.0- } \\
70.0) *\end{array}$ & $\begin{array}{c}37.9(32.5- \\
45.0)\end{array}$ \\
\hline $\begin{array}{l}\text { Concentratio } \\
\mathrm{n} \\
\text { of attention }\end{array}$ & $\begin{array}{c}279.1(230.0 \\
-320.0) *\end{array}$ & $\begin{array}{c}354.0(320.0 \\
-370.0) * \circ\end{array}$ & $\begin{array}{c}169.0(156.0 \\
-175.0) * \bullet\end{array}$ & $\begin{array}{c}491.2(390.0 \\
-430.0)\end{array}$ \\
\hline $\begin{array}{l}\text { Figurative } \\
\text { memory }\end{array}$ & $8.1(7.0-9.0)$ & $\begin{array}{c}6.2(5.9-6.8) \\
* \circ\end{array}$ & $\begin{array}{c}5.5(5.0-6.0) \\
* \bullet\end{array}$ & $8.4(8.0-9.0)$ \\
\hline $\begin{array}{l}\text { Indicator on } \\
\text { the scale of F } \\
\text { MMPI, (T- } \\
\text { scores) }\end{array}$ & $\begin{array}{c}68.5(59.0- \\
72.5) *\end{array}$ & $\begin{array}{c}85.3(79.6- \\
91.0) * \circ\end{array}$ & $\begin{array}{c}85.0(78.0- \\
91.2)^{*}\end{array}$ & $\begin{array}{c}58.2(37.0- \\
63.0)\end{array}$ \\
\hline $\begin{array}{l}\text { Indicator on } \\
\text { the scale of } 2 \\
\text { MMPI test, } \\
\text { (T-scores) }\end{array}$ & $\begin{array}{c}81.0(72.5- \\
87.6) *\end{array}$ & $\begin{array}{c}92.6(83.0- \\
101.0) * 0\end{array}$ & $\begin{array}{c}103.6(87.0- \\
112.0) *\end{array}$ & $\begin{array}{c}55.5(49.0- \\
59.0)\end{array}$ \\
\hline $\begin{array}{l}\text { Indicator on } \\
\text { the scale of } 8 \\
\text { MMPI test, } \\
\text { (T-scores) }\end{array}$ & $\begin{array}{c}81.0(68.0- \\
87.5) *\end{array}$ & $\begin{array}{c}100.2(90.2- \\
110.0) * \circ\end{array}$ & $\begin{array}{c}101.0(85.7- \\
114.0) *\end{array}$ & $\begin{array}{c}57.6(43.5- \\
62.5)\end{array}$ \\
\hline
\end{tabular}

Note: $*$ - the difference is statistically significant at $\mathrm{p}<0.05$ compared with the control group; ${ }^{\circ}$ - differences are statistically significant at $\mathrm{p}<0.05$ when compared to indicators of 1 and 2 groups; - - differences are statistically significant at $\mathrm{p}<0.05$ when compared to indicators of 2 and 3 groups.

The results of neuropsychological studies of AR Luria in patients with CMI and trained patients, working in contact with the mercury, with no signs of intoxication, state the disorder of cognitive function in $70 \%$ of cases of violations audioverbal, visual, non-volatile memory, reciprocal coordination, finger gnosis impressive speech, analytical and synthetic thinking. Such changes indicate involvement in the pathological process of the frontal, inferior temporal, parietal, occipital zones of the brain cortex, hippocampus, corpus callosum, the overlapping area of tertiary temporoparietal-occipital cortex of the left hemisphere [12]. In carrying out the discriminant analysis in terms of neuropsychological studies were identified 4 criteria progression mercury intoxication: level of visual and longterm memory, finger gnosis and impressive speech. F for inclusion indicators of obtained ranged from 15.5 for the level of visual memory $(p=0.001)$ - to $7.0(p=0.04)$ - for an impressive indicator of speech. By analyzing table 2 it can be assumed that the violation of higher cortical functions involving the occipital (visual memory), hippocampal (longterm memory), parietal (finger gnosis) and temporal (impressive speech) areas of the brain has been observed in the preclinical stage, because these indicators exceeded those values of the control group. Subsequently in the progression of mercury poisoning is observed worsening the functioning of the occipital and parietal lobes of the brain. There is a gradual increase in visual memory indicators of from 0.6 to 1.3 and 1.6 points $(\mathrm{p}<0.05)$, and indicator finger gnosis from 0.5 to 0.7 and 1.2 points ( $\mathrm{p}<0.05)$, by comparing the data between the 1, 2 or 3 groups, respectively (Table 2 ).

For a more objective confirmation presence progression of degenerative changes in the central and peripheral nervous system discriminant analysis was performed on the neurophysiological parameters studied groups. 
TABLE II. NEUROPSYCHOLOGICAL PERFORMANCE OF HIGHER MENTAL FUNCTIONS IN THE EXAMINED GROUPS, ME (Q25-Q75)

\begin{tabular}{|l|c|c|c|c|}
\hline $\begin{array}{c}\text { Indicators, } \\
\text { scores }\end{array}$ & $\begin{array}{c}\text { 1st group } \\
(\mathbf{n}=30)\end{array}$ & $\begin{array}{c}\text { 2nd group } \\
(\mathbf{n = 1 7 )}\end{array}$ & $\begin{array}{c}\text { 3rd group } \\
(\mathbf{n}=\mathbf{3 6})\end{array}$ & $\begin{array}{c}\text { Control } \\
\text { group } \\
(\mathbf{n}=\mathbf{3 0})\end{array}$ \\
\hline $\begin{array}{l}\text { Visual } \\
\text { memory }\end{array}$ & $0.6(0-1.0)^{*}$ & $\begin{array}{c}1.3(0-2.0)^{*} \\
\circ\end{array}$ & $\begin{array}{c}1.6(0-3.0) \\
* \bullet\end{array}$ & $0.3(0-0.6)$ \\
\hline $\begin{array}{l}\text { Long-term } \\
\text { memory }\end{array}$ & $\begin{array}{c}1.9(1.0- \\
3.0)\end{array}$ & $\begin{array}{c}2.2(1.0- \\
3.0)^{*}\end{array}$ & $\begin{array}{c}2.2(2.0- \\
3.0) *\end{array}$ & $0.3(0-0.6)$ \\
\hline $\begin{array}{l}\text { Finger } \\
\text { gnosis }\end{array}$ & $\begin{array}{c}0.5(0-1.0) \\
*\end{array}$ & $\begin{array}{c}0.7(0-1.0) \\
* \circ\end{array}$ & $\begin{array}{c}1.2(0-2.0)^{*} \\
\bullet\end{array}$ & 0 \\
\hline $\begin{array}{l}\text { Impressive } \\
\text { speech }\end{array}$ & $1.0(0-2.0)$ & $1.2(0-2.0)^{*}$ & $1.0(0-2.0)^{*}$ & $0.3(0-0.6)$ \\
\hline
\end{tabular}

Note: $*$ - the difference is statistically significant at $\mathrm{p}<0.05$ compared with the control group; ${ }^{\circ}$ - differences are statistically significant at $\mathrm{p}<0.05$ when compared to indicators of 1 and 2 groups; $\bullet$ - differences are statistically significant at $\mathrm{p}<0.05$ when compared to indicators of 2 and 3 groups

The result of discriminant analysis were 4 prognostic criteria with a significance level of 0.045 to 0.002 : indicator N11 of somatosensory evoked potentials (ms), latency of P300 cognitive evoked potentials (ms), the power of the alpha rhythm on the EEG (\%), the latency of P2 visual evoked potentials (ms). The most informative feature is the indicator $\mathrm{N} 11$ somatosensory evoked potentials $(\mathrm{F}=6.9)$. Deceleration of the impulse at the thickening of the cervical spinal cord (N11 peak somatosensory evoked potentials), may indicate demyelinating process, and it was found in 1,2 or 3 groups, compared with the indicator in the control group $(\mathrm{p}<0.05)\left(3^{\text {rd }}\right.$ table). In addition, the surveyed persons 1,2 and 3 groups was observed lengthening of latent P2 visual evoked potentials: 306.0 (260.0-320.0); 264.0 (220.0-280.0) and $432.3(390.0-459.0) \mathrm{ms}$, respectively, in groups compared with the control group (187.1 (140.0-210.0) ms), ( $\mathrm{p}<0.05$ ), indicating that conduction disturbance impulse at the thalamus and brain stem structures. With increasing mnestic-intellectual deficit, compounded by parallel indicators reflecting cognitive function - the peak latency of $\mathrm{P} 300$ to 354.2 (320.0-370.0) $\mathrm{ms}$ in group 2 to 432.3 (390.0459.0 ) in group 3 , and reduced representation of alpha rhythm on the EEG from $32.9 \%$ in groups 1 and 2 to $26.3 \%$ in group $3(\mathrm{p}<0.05)$, due to the prevalence of slow-wave activity (Table 3 ).

The research allowed to establish basic criteria for progression of clinical symptoms, neurological and psychopathological disorders in patients with mercury intoxication. The main markers of pathological changes in the early stages of the disease among trained workers exposed to mercury for more than 10 years, are: exceeding the normative values of 2 and 8 of the MMPI scales by 70 points or more, the level depression by V. Zung from 54 points or more, reducing the concentration of attention - 279 points or less, the increase of long-term, visual memory, finger gnosis and impressive speech from 0.5 points and above, as well as increased the latency peak N11 somatosensory evoked potentials, of $12 \mathrm{~ms}$ and higher, P2 visual evoked potentials from $260.0 \mathrm{~ms}$ and higher and decrease in the index alpha rhythm EEG below $32.0 \%$. With the combination of all four of these indicators of the likelihood of mercury intoxication is $91.3 \%$.
TABLE III. THE NEUROPHYSIOLOGICAL PARAMETERS IN THE EXAMINED GROUPS, ME (Q25-Q75)

\begin{tabular}{|c|c|c|c|c|}
\hline $\begin{array}{c}\text { Indicators, } \\
\text { scores }\end{array}$ & $\begin{array}{c}\text { 1st group } \\
(\mathbf{n}=30)\end{array}$ & $\begin{array}{l}\text { 2nd group } \\
\quad(n=17)\end{array}$ & $\begin{array}{l}\text { 3rd group } \\
\quad(n=36)\end{array}$ & $\begin{array}{c}\text { Control } \\
\text { group } \\
(\mathbf{n}=\mathbf{3 0})\end{array}$ \\
\hline $\begin{array}{l}\text { The } \\
\text { latency of } \\
\mathrm{N} 11,(\mathrm{~ms})\end{array}$ & $\begin{array}{l}12.6(11.7- \\
13.5)^{*}\end{array}$ & $\begin{array}{l}12.8(12.0- \\
13.8)^{*}\end{array}$ & $\begin{array}{l}12.7(12.0- \\
13.3)^{*}\end{array}$ & $\begin{array}{l}11.3(10.9- \\
11.9)\end{array}$ \\
\hline $\begin{array}{l}\text { The } \\
\text { latency of } \\
\text { P300, (ms) }\end{array}$ & $\begin{array}{l}309.7(280.0- \\
330.0)\end{array}$ & $\begin{array}{l}354.2(320.0- \\
370.0)^{*} \circ\end{array}$ & $\begin{array}{l}432.3(390.0- \\
459.0)^{*} \bullet\end{array}$ & $\begin{array}{l}305.4(270.0- \\
315.0)\end{array}$ \\
\hline $\begin{array}{l}\text { The } \\
\text { latency of } \\
\text { P2 VEP, } \\
(\mathrm{ms})\end{array}$ & $\begin{array}{l}306.0(260.0- \\
320.0)^{*}\end{array}$ & $\begin{array}{l}264.0(220.0- \\
280.0)^{*}\end{array}$ & $\begin{array}{l}298.0(260.0- \\
330.0)^{*} \bullet\end{array}$ & $\begin{array}{l}187.1(140.0- \\
210.0)\end{array}$ \\
\hline $\begin{array}{l}\text { The power } \\
\text { of alpha } \\
\text { rhythm on } \\
\text { the EEG } \\
(\%)\end{array}$ & $\begin{array}{l}32.9(31.0- \\
41.0)^{*}\end{array}$ & $\begin{array}{l}32.9(30.0- \\
41.0)^{*}\end{array}$ & $\begin{array}{l}26.3(20.0- \\
32.0) * \bullet\end{array}$ & $\begin{array}{l}48.3(42.0- \\
63.0)\end{array}$ \\
\hline
\end{tabular}

Note: * - the difference is statistically significant at $\mathrm{p}<0.05$ compared with the control group; ${ }^{\circ}$ - differences are statistically significant at $\mathrm{p}<0.05$ when compared to indicators of 1 and 2 groups; $\bullet$ - differences are statistically significant at $\mathrm{p}<0.05$ when compared to indicators of 2 and 3 groups.

In forming the professional of chronic mercury intoxication stage 1 and 2 criteria for progression are raising depression according to $\mathrm{V}$. Zung score from 64.9 and higher and T-score scale from 2 to MMPI 92.6 points and above, decline in the figurative memory from 6.2 points or less; visual memory scores of 1.3 and above and finger gnosis of 0.7 points or higher by A.R. Luria; an increase in latency of P300 more than $350 \mathrm{~ms}, \mathrm{P} 2$ visual evoked potentials more than $264.0 \mathrm{~ms}$, decrease in the index of Alpha rhythm below $32.0 \%$. With the combination of all four of these indicators the likelihood of progression of neurological and psychiatric symptoms is $96.1 \%$.

\section{CONCLUSION}

To predict the development of psycho-neurological symptoms, patients in contact with the mercury, it is necessary to conduct an annual comprehensive examination, including SMIL test to determine the level of depression on W. Zung, concentration using proofreading sample "Landolt Ring", the level of long-term memory and visual, finger gnosis and impressive speech, AR Luria and somatosensory, visual and cognitive evoked potentials and electroencephalography.

\section{REFERENCES}

[1] E.V. Katamanova, O.I. Shevchenko, O.L. Lachman, I.A Denisova, "Cognitive impairment in patients with chronic mercury intoxication», Medicine of work and industrial ecology, vol. 4, 2014, pp. 7-12.

[2] N.F. Izmerov. Professional pathology. National leadership: GEOTAR: Media, 2011, pp.325-420.

[3] L. Soleo, M.L. Urbano, V. Petrera, L.Ambrosi. «Effects of low exposure to inorganic mercury on psychological performance», British Journal of Industrial Medicine, vol. 47, 1990, pp. 105-109.

[4] K.O. Yeates, M.E. Mortensen, «Acute and chronic neuropsychological consequences of mercury vapor poisoning in two early adolescents», J. Clin. Exp. Neuropsychol, vol. 16(2), 1994, pp. 209-222. 
[5] E.V. Katamanova, T.N. Konstantinova, O.K. Andreyeva, I,A. Brezhneva, «Neurophysiological diagnostic criteria neurointoxications», Proceedings of the Samara Scientific Center of the Russian Academy of Sciences, vol. 13(7), 2011, pp. 1702-1705.

[6] D.V. Rusanova, O.L. Lachman, «Changing the status of the central and peripheral conductive structures in patients in the late period of chronic mercury intoxication», Medicine of work and industrial ecology, vol. 5, 2015, pp.14-17.

[7] E.D. Khomskaya Neuropsychology: 4th Edition: SPb: Peter; 2007, p. 197-240.

[8] V.B. Shapar, A.V. Timchenko, V.N. Shvydchenko, Practical psychology. Toolkit: Rostov - on Don:"Phoenix", 2002. pp. 35-86.
[9] V. Borovikov Statistica: the art of data analysis on the computer: SPb: JSC "Peter Buck", 2001. pp. 320-329.

[10] Eto Komyo, Y. Takizawa, H. Akagi, et al., «Differential Diagnosis between Organic and Inorganic Mercury Poisoning in Human Cases - The Pathologic Point of View», Toxicologic pathology, vol. 27(96), 1999, pp. $664-671$.

[11]K. Janet Kern «Evidence of parallels between mercury intoxication and the brain pathology in autism», Acta Neurobiol. Exp, vol. 72, 2012, pp. 113-153.

[12] O.I. Shevchenko, E.V. Katamanova, O.L. Lachman, «Features psychopathological changes in patients with chronic mercury intoxication», Doktor.ru, vol. 8(109)9(110), 2015, pp. 65-70. 
